9. Масленникова Л.В., Майкова С.Э., Окунев Д.В. Системно-структурный подход к процессу обучения в высших учебных заведениях // Психология и педагогика: методика и проблемы практического применения. 2016. № 48. С. 88-92.

10. Ильина Т.А. Структурно-системный подход к организации обучения. Вып. 2. М.: Знание, 1972. 88 с.

11. Косихина О.С. Системно-структурный подход к усвоению знаний в средней школе: дис. ... канд. пед. наук. Барнаул, 2006. 171 с.

12. Морева Н.А. Технологии профессионального образования: учеб. пособие для студ. высш. учеб. зав. М.: Издательский центр «Академия», 2005. 432 с.

13. Беликов В.А. Образование. Деятельность. Личность: монография. М.: Академия Естествознания, $2010.340 \mathrm{c}$.
14. Дьюи Дж. Школа и общество. М.: Госиздат, 1924. $168 \mathrm{c}$.

15. Коджаспирова Г.М., Коджаспиров А.Ю. Педагогический словарь: для студентов высших и средних педагогических учебных заведений. М.: Издательский центр «Академия», 2001. 176 с.

16. Кузьмина Н.В. Предмет акмеологии. СПб.: Политехника, 2002. 198 с.

17. Ананьев Б.Г. О проблемах современного человекознания. СПб.: Питер, 2001. 272 с.

18. Акмеология: методология, методы и технологии (материалы научной сессии, посв. 75-летию члена-корреспондента РАО, Президента МААН Н.В. Кузьминой) / под общ. ред. А.А. Деркача. М.: РАГС, 1998. $230 \mathrm{c}$.

\title{
THE SYSTEM OF FORMATION OF READINESS \\ TO SELF-EDUCATIONAL ACTIVITY FOR PROSPECTIVE BACHELORS MAJORING IN MECHANICAL ENGINEERING
}

\author{
Podnebesova Mariya Igorevna, senior lecturer of Informatics and Control Systems Department \\ Branch of Samara State Technical University (Syzran, Samara Region, Russian Federation)
}

Abstract. The paper deals with the problem of professional training of technical University bachelors majoring in Engineering. The author proves that it is necessary to develop prospective specialists' ability to self-education. The author presents an efficient system of self-educational activity development for prospective bachelors majoring in engineering by means of information and communication technologies and active methods of teaching «Informatics» including a special component, facilitating the development of indicators in the structure of readiness. The system of self-educational activity development for prospective bachelors majoring in engineering is a form of educational system that includes methodological, substantive, procedural and efficient elements. The principles of systemicstructural, acmeological and competency approaches are fundamental and allow designing the components of the system and choosing the appropriate means of readiness development. The specific of professional activity of bachelors majoring in engineering is the reason for choice of «Informatics» as a means of readiness formation. These materials can serve as the basis for students' educational activity organization and monitoring the quality of their professional training.

Keywords: bachelor of engineering; readiness for self-educational activity; systemic-structural, activity and acmeological approaches; system of formation of readiness to self-educational activity for future bachelors in mechanical engineering; acmeological technologies; active methods of teaching.

\section{УДК 378.1}

\section{ИЗУЧЕНИЕ ГОТОВНОСТИ ВЫПУСКНИКОВ ПЕДАГОГИЧЕСКОГО ВУЗА К ОРГАНИЗАЦИИ НРАВСТВЕННОГО САМОВОСПИТАНИЯ ШКОЛЬНИКОВ}

(C) 2017

Полухина Марина Олеговна, кандидат педагогических наук,

преподаватель кафедры лингвистики, межкультурной коммуникации и русского языка как иностранного Самарский государственный технический университет (2. Самара, Российская Федерация)

Аннотация. В данной статье рассматриваются результаты проведенной экспериментальной работы по формированию готовности студента - будущего учителя к организации нравственного самовоспитания школьников. Описываются изменения, произошедшие в когнитивном, мотивационно-ценностном, деятельностном компонентах готовности будущих учителей к организации нравственного самовоспитания школьников. Так, когнитивный компонент готовности изучался с помощью метода понятийного словаря, мотивационно-ценностный компонент готовности будущего учителя изучался с помощью методики В.А. Ядова «Ценностные ориентации», деятельностный компонент готовности - с помощью авторской анкеты. В статье представлены результаты сравнения изменений в представлениях студентов о морали, ценности, нравственном идеале, нравственном самовоспитании, а также о методах нравственного самовоспитания, методах нравственного просвещения и методах формирования опыта нравственного поведения, полученные на контрольном этапе экспериментальной работы. Представлены изменения, произошедшие в мотивационно-ценностной сфере сознания студентов. Выявлено, что выпускники ориентированы на внутреннюю мотивацию деятельности по организации нравственного самовоспитания школьников, а не на внешнюю, как это было на констатирующем этапе экспериментальной работы. В процессе экспериментальной работы изменились представления выпускников об умениях, образующих содержание деятельностного компонента готовности, которые теперь основываются на научном знании. 
Ключевые слова: готовность; выпускники; педагогический вуз; нравственное самовоспитание школьников; когнитивный компонент; мотивационно-ценностный компонент; деятельностный компонент; метод понятийного словаря; методика В.А. Ядова «Ценностные ориентации»; авторская анкета; ценности; мораль; нравственный идеал; умения.

В условиях глобализации современного мира существует необходимость утверждения в обществе идеалов нравственности. В настоящее время в образовании прослеживается тенденция формирования интеллектуально развитой, конкурентоспособной, успешной личности, что, в свою очередь, может привести к забвению морали, одним из результатов которого станет увеличение числа людей, эгоцентричных и равнодушных к нуждам и чаяниям другого человека. Появлению таких людей может и должно противостоять целенаправленно организованное воспитание детей, подростков и юношей, эффективность которого во многом зависит от самовоспитания [1].

Проблема самовоспитания, нравственного самовоспитания личности - это не новая научная проблема. Многие ученые, такие как В.В. Байлук [2], Д.С. Блекки [3], Л.И. Игнатовский [4], П.П. Киселев [5], С.М. Ковалев [6], А.В. Резниченко [7], Л.И. Рувинский [8], М.Г. Тайчинов [9], С.Б. Елканов [10], Р.И. Мазитова [11], Н.И. Никитина [12], занимались изучением данного явления.

Актуальным становится поиск способов развития у школьников нравственности как «совокупности этических требований, которые индивид должен предъявлять к себе сам» [13]. Одним из возможных способов развития нравственности является организация учителем нравственного самовоспитания учащихся. Таким образом, перед педагогическими вузами возникает проблема формирования готовности будущего учителя к организации нравственного самовоспитания школьников.

Цель данной статьи представить результативность экспериментальной работы по формированию готовности будущего учителя к организации нравственного самовоспитания школьников.

Экспериментальная работа со студентами - будущими учителями осуществлялась на протяжении четырех лет их обучения в педагогическом вузе (со второго по пятый курс). Готовность выпускников к организации нравственного самовоспитания школьников изучалась с использованием методов научнопедагогического исследования, аналогичных методам, с помощью которых изучалась такая готовность второкурсников. Сравнив результаты констатирующего этапа экспериментальной работы с результатами контрольного ее этапа, мы сделали выводы о результативности экспериментальной работы по формированию готовности будущих учителей к организации нравственного самовоспитания школьников.

Экспериментальная работа проводилась на базе факультета иностранных языков ФГБОУ ВПО «Поволжская государственная социально-гуманитарная академия». Для участия в экспериментальной работе были отобраны 80 студентов второго курса. В силу различных обстоятельств из данного количества будущих учителей окончили вуз 74 человека.

Логика программы нашего исследования, а также теоретического анализа полученных данных базируется на теоретических положениях о структуре готовности учителя к организации нравственного самовоспитания школьников и содержании ее компо- нентов (когнитивного, мотивационно-ценностного и деятельностного).

Когнитивный компонент готовности изучался с помощью метода понятийного словаря. Использование этого метода дало возможность выявить знание выпускников о морали, ценности, нравственном идеале, нравственном самовоспитании школьников, а также о методах нравственного самовоспитания, методах нравственного просвещения и методах формирования опыта нравственного поведения школьников. Содержание данного знания выпускников претерпело изменения по сравнению со знанием второкурсников о вышеперечисленных явлениях, анализ которых (изменений) позволяет утверждать, что такое знание дает возможность студентам обоснованно осуществлять выбор путей и средств организации нравственного самовоспитания школьников: «Ценности освящают твой выбор, знания обосновывают его» [14, с. 20].

Суть таких изменений заключается в том, что, если на констатирующем этапе экспериментальной работы представления студентов базировались в основном на ощущении и восприятии, свойственным обыденному уровню сознания студентов, основанного на жизненном опыте, то на контрольном этапе экспериментальной работы представления студентов о названных понятиях и методах являются систематизированными и научно осмысленными. Будущие учителя не смешивают содержание понятий между собой, не подменяют одно другим, видят различия между конкретными методами. Так 44,59\% выпускников осознают императивный (повелительный) характер морали; 21,62\% будущих учителей, осознавая оценочный характер морали, полагают, что мораль есть критерий для оценивания деятельности человека, его мыслей и намерений. 59,46\% будущих учителей полагают, что ценность есть значение для человека как субъекта предмета, явления и т.д.; 32,43\% выпускников рассматривают ценность как отношение человека к другому человеку или к явлению, предмету и т.д. Количество студентов, связывающих идеал с образом (образцом), отражающим совокупность нравственных ценностей, увеличилось с $28,75 \%$ до 47,30\%. 35,13\% выпускников видят в идеале нравственный образец поведения, к которому необходимо стремиться. $17,57 \%$ студентов, рассматривающих идеал как отражение норм общественной морали в нравственном мире человека, осознают социальную детерминированность идеала.

Установлено, что если на констатирующем этапе экспериментальной работы студенты не связывали нравственное самовоспитание с нравственной деятельностью, с нравственным совершенством, с воспитанием в себе нравственных качеств, то на контрольном ее этапе 50,00\% выпускников понимают нравственное самовоспитание как самостоятельную, осознанную, систематическую деятельность по воспитанию у себя нравственных качеств. 18,92\% выпускников видят взаимосвязь воспитания как приобщения к ценностям и нравственного самовоспитания, осознаваемого ими как самостоятельное форми- 
рование у себя системы нравственных ценностей, определяющих поведение человека. 13,51\% будущих учителей связывают нравственное самовоспитание с нравственным совершенством.

В ответах выпускников на вопрос о методах нравственного самовоспитания школьников также произошли изменения.

Суть изменений заключается в уменьшении количества названных студентами методов самовоспитания с 43 до 16, из которых собственно методами нравственного самовоспитания являются 10; в повышении количества названных студентами собственно методов нравственного самовоспитания с 6 до 10. Значительная часть выпускников не смешивают методы самовоспитания с формами, средствами обучения и воспитания, с психологическими механизмами регуляции поведения, с качествами личности, с видами воспитания, как это было на констатирующем этапе экспериментальной работы.

Результаты контент-анализа ответов выпускников на вопросы «Какие методы нравственного просвещения школьников вы знаете?» и «Какие методы формирования опыта нравственного поведения школьников вы знаете?» также указывают на изменения, произошедшие в представлениях будущих учителей о методах нравственного просвещения и методах формирования опыта нравственного поведения.

Суть таких изменений заключается в уменьшении количества названных студентами методов нравственного просвещения с 30 до 18, методов формирования опыта нравственного поведения - с 15 до 12; в увеличении количества названных студентами собственно методов нравственного просвещения с 6 до 15 , собственно методов формирования опыта нравственного поведения - с 3 до 10. Отсутствуют студенты, затруднившиеся назвать данные методы (ранее таких студентов было 10,00\% и 48,75\% соответственно). Студенты осознают, что научное знание «приращивается» [15] к нравственной его составляющей, которая придает нравственную ориентацию научному знанию. Выпускники не смешивают методы нравственного просвещения и методы формирования опыта нравственного поведения с формами, средствами обучения и воспитания, с психологическими механизмами регуляции поведения и т.д., как это было на констатирующем этапе экспериментальной работы.

Мотивационно-ценностный компонент готовности будущего учителя к организации нравственного самовоспитания учащихся изучался с помощью методики В.А. Ядова «Ценностные ориентации» [16, c. 208-209]. Будущим учителям был предложен список ценностей, образующих содержание мотивационно-ценностного компонента готовности.

В ходе исследования были выявлены следующие изменения: если на констатирующем этапе экспериментальной работы студенты были ориентированы на внешнюю мотивацию при организации нравственного самовоспитания школьников (ценность «интерес» занимала 2 ранг, а ценность «соучастие» 6 ранг), то на контрольном ее этапе они ориентированы на внутреннюю мотивацию деятельности по организации нравственного самовоспитания учащихся (ценность «соучастие» занимает 2 ранг, а ценность «интерес» 6 ранг). Если на констатирующем этапе экспериментальной работы студенты связывали от- ветственность с выполнением обязанностей (учитель обязан организовывать нравственное самовоспитание школьников), и им было важно осуществлять деятельность, которая им интересна, то на выпускном курсе студенты осознают, что ответственность учителя есть его отношение к учащемуся. Ответственность, как пишет Н. Гартман, состоит «не только в субъективной убежденности личности, но и в реальном нравственном поведении, которым она как бы делает вывод из своей убежденности. Хотя это реальное поведение и чисто внутреннее, но, несмотря на это, имеет решающее значение в нравственной жизни» $[17$, с. 623$]$. Ответственность учителя как отношение проявляется в соучастии в нравственном развитии школьника. Выпускники стремятся проникнуть во внутренний мир ученика, прочувствовать его проблемы и помочь найти пути их решения. Критерием проявления подлинного соучастия является совесть (3 ранг), напоминающая учителю «о его моральных обязанностях, об ответственности, которую он несет перед другими и перед собой» [18, с. 301]. Также совесть является, как подчеркивает Т.В. Мишаткина, индикатором, определяющим соответствие индивидуального поведения личности высшим моральным предписаниям [19, с. 201]. Ценность «совесть» переместилась с 5 на 3 ранг в ценностной иерархии студентов.

В результате сравнения выявленных на контрольном этапе экспериментальной работы прямых и обратных связей между ценностями с обнаруженными на констатирующем ее этапе прямыми и обратными связями между ценностями установлено: а) усиление прямой связи между достоинством и честью с 0,2667 до 0,5602 ; б) появление новых прямых связей, а именно прямых связей между долгом и содействием $(\mathrm{R}=0,3509)$, ответственностью и совестью $(\mathrm{R}=0,3632)$; в) уменьшение количества обратных связей между содействием и остальными ценностями с 5 до 2, между соучастием и остальными ценностями с 5 до 1.

Выпускники понимают, что, стремясь содействовать школьнику в его нравственном развитии, соучаствуя в этом процессе через организацию нравственного самовоспитания учащихся, педагог выполняет свой долг, руководствуясь при этом совестью и неся ответственность за свои действия по организации нравственного самовоспитания ученика. Противоречия в мотивационной сфере сознания выпускников имеют тенденцию к разрешению. Ценности «содействие» и «соучастие» находятся в непосредственной близости друг от друга на ценностной шкале ценностей, образующих содержание мотивационно-ценностного компонента готовности будущего учителя к организации нравственного самовоспитания школьников.

Деятельностный компонент готовности учителя к организации нравственного самовоспитания школьников изучался с помощью авторской анкеты, которая использовалась и на констатирующем этапе экспериментальной работы. В результате изучения были выявлены изменения, произошедшие в этом компоненте готовности.

Суть таких изменений при сохраняющейся востребуемости студентами на контрольном этапе экспериментальной работы, так же как и на констатирующем ее этапе, умения анализировать свою деятельность по организации нравственного самовоспи- 
тания школьников (средний индекс важности равен 0,7635), заключается в а) увеличении числовых значений среднего индекса важности, среднего индекса уверенности всех без исключения умений; б) уменьшении количества студентов, для которых владение тем или иным умением скорее не важно, чем важно или вовсе не важно; которые скорее не владеют данным умением или уверены, что не владеют совсем, и соответственно увеличение количества будущих учителей, для которых владение умением важно или скорее важно, чем не важно, которые уверены, что владеют конкретным умением или скорее владеют; в) уменьшении количества студентов, не определившихся относительно значимости для них того или иного умения при организации нравственного самовоспитания школьников.

Выпускники видят пути развития у школьников мотива нравственного самовоспитания как опредмеченной потребности учащегося в нравственном совершенствовании. Они не только осознают, что «выбор того, что является безусловным благом для других, есть выбор моральных ценностей» [20, с. 39], которые становятся для учащихся критериями рефлексии своего внутреннего мира и своих отношений с людьми, но и владеют способами развития у школьников способности к такой рефлексии.

Таким образом, полученное эмпирическое знание свидетельствует о результативности экспериментальной работы по формированию готовности студента - будущего учителя к организации нравственного самовоспитания школьников.

\section{СПИСОК ЛИТЕРАТУРЫ:}

1. Смоляр А.И. Формирование профессиональной готовности студентов педвуза к руководству самовоспитанием школьников: дис. ... канд. пед. наук. M., 1987. 233 c.

2. Байлук В.В. Воспитание и самовоспитание // Педагогическое образование в России. 2014. № 1. С. $156-159$.

3. Блекки Д.С. Самовоспитание умственное, физическое и нравственное. СПб.: Изд. Риккера К., $1891.128 \mathrm{c}$.

4. Игнатовский Л.И. Нравственное самовоспитание личности в условиях развитого социализма. М.: Высшая школа, 1979. 135 с.
5. Киселев В.П. Нравственное самовоспитание. М.: Знание, 1977. 64 с.

6. Ковалев С.М. Воспитание и самовоспитание. М.: Мысль, 1986. 288 с.

7. Резниченко А.В. Профессионально-нравственное самовоспитание студентов как условие развития педагогической культуры будущего учителя: дис. ... канд. пед. наук. Ростов н/Д, 1999. 196 с.

8. Рувинский Л.И. Самовоспитание личности. М.: Мысль, 1984. 140 с.

9. Тайчинов М.Г. Воспитание и самовоспитание школьников: книга для учителя. М.: Просвещение, $1982.160 \mathrm{c}$.

10. Елканов С.Б. Основы профессионального самовоспитания будущего учителя. М.: Просвещение, 1989. 189 c.

11. Мазитова Р.И. Самовоспитание и самообразование личности // Проблемы и перспективы развития образования в России. 2014. № 26. С. 11-15.

12. Никитина Н.И. Профессиональное самовоспитание будущих социальных педагогов в системе непрерывного образования: дис. ... д-ра пед. наук. М., 2004. $328 \mathrm{c}$.

13. Бондырева С.К., К Колесов Д.В. Нравственность. М.: МПСУ; Воронеж: НПО «МОДЭК», 2006. $336 \mathrm{c}$.

14. Сагатовский В.Н. Философия развивающейся гармонии (философские основы мировоззрения): в 3 ч. Ч. 3. Антропология. СПб.: Петрополис, 1999. $288 \mathrm{c}$.

15. Блауберг И.В. Проблема целостности и системный подход. М.: Эдиториал УРСС, 1977. 448 с.

16. Саморегуляция и прогнозирование социального поведения личности / под ред. В.А. Ядова. Л.: Наука, 1979. 264 с.

17. Гартман Н. Этика. СПб.: Владимир Даль, 2002. $707 \mathrm{c}$.

18. Золотухина-Аболина Е.В. Современная этика: учебное пособие для студентов вузов. Ростов-наДону: МарТ, 2005. 416 с.

19. Этика / под ред. Т.В. Мишаткиной, Я.С. Яскевича. Мн.: Новое знание, 2002. 509 с.

20. Шрейдер Ю.А. Этика. М.: Текст, 1998. 271 с.

\section{THE STUDY OF PEDAGOGICAL UNIVERSITY GRADUATES' READINESS TO ORGANIZE SCHOOL STUDENTS' MORAL SELF-EDUCATION}

(C) 2017

Polukhina Marina Olegovna, candidate of pedagogical sciences,

lecturer of Linguistics, Cross-cultural Communication and Russian as a Foreign Language Department Samara State Technical University (Samara, Russian Federation)

Abstract. The paper presents the results of the experimental work on development of student-pre-service teacher's readiness to organize school students' moral self-education. The author describes the variations that took place in cognitive, motivational-axiological and activity components of pre-service teacher's readiness to organize moral selfeducation of school-students. A cognitive component was studied by the method of conceptual vocabulary; the value orientation method developed by V.A. Yadov was used for motivational-axiological component and there was a questionnaire for activity component. The paper reveals the comparative results of variations in students' perceptions about morals, values, moral ideal, moral self-education, as well as the methods of moral self-education, moral education methods and methods of moral behavior experience development received at the control stage of the experiment. The paper also presents changes that have occurred in the motivational-axiological sphere of students' consciousness. It has been found that students are now focused on the intrinsic motivation of activity when organizing moral self-education of school students rather than on the external one. In the activity-component during the experimental 
work, the perceptions about skills have changed in the graduates' consciousness, which are now based on scientific knowledge.

Keywords: readiness; graduates; pedagogical university; moral self-education of school students; cognitive component; motivational-axiological component; activity component; value orientation method developed by V.A. Yadov; questionnaire; values; moral; moral ideal; skills.

УДК 378.14

\section{ОБУЧЕНИЕ СТУДЕНТОВ - БУ ДУЩИХ УЧИТЕЛЕЙ ФИЗИКИ УПРАВЛЕНИЮ ИНТЕЛЛЕКТУАЛЬНЫМ РАЗВИТИЕМ ШКОЛЬНИКОВ В ПРОЦЕССУАЛЬНОМ ПЛАНЕ} (C) 2017

Самойлов Евгений Андреевич, доктор педагогических наук, профессор кафедры физики, математики и методики обучения

Самарский государственный сочиально-педагогический университет (2. Самара, Российская Федераиия)

Аннотация. В статье анализируются различные подходы к управлению интеллектуальным развитием учащихся при обучении физике в школе, обусловленные, с одной стороны, многообразием психологических трактовок интеллекта и моделей его становления, а с другой стороны, используемой в рамках исследования методологической установкой (классической, неклассической или постнеклассической). Дается описание предложенной автором процессуальной модели управления интеллектуальным развитием обучаемых (УИРО), которая построена в соответствии с постнеклассическим типом рациональности на основе холистического (целостного) понимания природы интеллекта, учитывающей ценности информационного общества и влияние коллектива учеников на результативность индивидуальной образовательной деятельности при обучении физике. С процессуальной точки зрения УИРО - это регулирование последовательной смены образовательных состояний неоднородного коллектива учеников, которое приводит к желаемому обогащению интеллектуальных ресурсов каждого школьника при усвоении физики. Предложенная процессуальная модель УИРО позволяет разработать рекомендации по эффективному адаптивному обучению физике школьников с учетом закономерностей интеллектуального развития и специфики функционирования холонических организационных систем. Описанный автором подход к управлению интеллектуальным развитием обучаемых является предметом изучения для студентов - будущих учителей физики в рамках формирующего педагогического эксперимента в СГСПУ.

Ключевые слова: интеллект; управление индивидуальным интеллектуальным развитием при обучении физике; коллективный развивающийся субъект; процессуальная модель управления интеллектуальным развитием школьников.

Готовность студентов - будущих учителей физики к управлению интеллектуальным развитием обучаемых (УИРО) становится важнейшим направлением их подготовки. Основополагающая роль управленческих умений такого вида обусловлена: 1) особенностями информационного общества, увеличением доли холонических социальных и производственных организаций, построенных на принципах коммуникации, новаторства, конструктивного партнерства и распределения ответственности [1]; 2) значимостью интеллектуального потенциала страны для ее конкурентоспособности и поступательного развития в современном динамичном непредсказуемом мире.

Изучение обширной научно-методической литературы приводит выводу о том, что проблема управления развитием интеллекта школьников при обучении физике на разных временных отрезках трактовалась и решалась по-разному, причем в явном виде никем из исследователей не ставилась. Это объясняется сложностью понимания психической природы интеллекта и, как следствие, многозначностью самого понятия «интеллект», что нашло отражение в тематике научных исследований в области методики обучения физике.

Большой пласт исследований в дидактике физики посвящен становлению таких интеллектуальных функций, как решение задач [2; 3 и др.], самоуправление при выполнении учебной деятельности [4; 5 и др.], самоорганизация при постановке разных видов эксперимента [6; 7 и др.] саморегуляция в ходе ана- лиза и перекодирования информации [8; 9 и др.] Однако нам не известны работы, в которых бы изучалось влияние коллектива на результаты интеллектуальной деятельности школьников при усвоении курса физики.

На рубеже веков в дидактике физики активизировались исследования, в основу которых положены современные перспективные психологические модели интеллекта. Представляют интерес методика развития дивергентных, конвергентных способностей и обучаемости учащихся основной школы при усвоении физического содержания [10], методика дифференцированного обучения физике на основе учета когнитивных стилей учеников [11], подходы к формированию информационных умений школьников как важных составляющих индивидуального когнитивного опыта $[12 ; 13]$. Однако все эти исследования проведены в русле классической стратегии расчленения интеллекта на составляющие элементы. Сегодня возникает необходимость в построении обобщенной концепции УИРО, интегрирующей достижения последних десятилетий в дидактике физики на основе идей взаимосвязи интеллектуального и духовного развития и влияния ученического коллектива на результативность образовательной деятельности.

Решение задачи УИРО в системе физического образования во многом детерминируется господствующей методологической установкой (типом рациональности). В.С. Степин выделил применительно к научному познанию три типа рациональности: клас- 